\section{Ueber den Gebrauch von Bernsteinsäure in der Alkalimetrie.}

Von Docent Dr. Emil Petersen, Kopenhagen.

Zur schnellen und bequemen Feststellung der Titer von Säuren oder Basen in der Alkalimetrie, eine Frage, die noch jetzt auf der Tagesordnung steht, sind bekanntlich mehrere Substanzen vorgeschlagen worden, doch sind die bisher geprüften entweder nicht hinlänglich genau oder sie müssen durch verschiedene Manipulationen vorbereitet werden, welche theils umständlich sind, theils zu Verlust und Feblern Veranlassung geben können.

Die Stärke von beispielsweise Natronlauge oder Barytwasser lässt sich sehr bequem und für fast alle $\mathrm{Zwecke}$ mit hinlänglicher Genauigkeit feststellen mittels Bernsteinsäure (gew.), die jetzt im Handel mit genügender Reinheit vorkommt. Ich habe mit einem von Kahlbaum i. J. 1894 bezogenen Präparat gearbeitet. Dasselbe wurde so wie es war, also ohne Umkrystallisiren, benutzt. Nur musste die Säure vor dem $A b$ wägen bei niedriger Temperatur (ca. $70^{\circ}$ ) getrocknet werden, um Feuchtigkeit (etwa $1 / 2$ Proc.) zu entfernen. Die Prüfung ihrer Brauchbarkeit zu dem in Rede stehenden Zweck geschah auf folgende Weise:

Eine reine, ca. 1-normale Chlorwasserstoffsäure wurde gewichtsanalytisch genau bestimmt durch Fäliung mit Silbernitrat und Wägung des Chlorsilbers. Diese Methode zur Titerstellung einer Normalsäure ist zweifellos die zur Zeit genaueste.

Mit dieser Säure wurde das Molecularvolumen von ca. 1/5-Normal-Barytwasser und von ca. $1 / 2$-Normal-Natronlauge titrimetrisch mittels Phenolphtaleïn bestimmt, indem von der Säure bez. ca. $10 \mathrm{~g}$ und ca. $25 \mathrm{~g}$ genau abgewogen und die Basen mit vorher durchgeprüften Geissler'schen Büretten abgemessen wurden. Gleich nach jeder Bestimmung wurde dieselbe mit soviel getrockneter und genau gewogener Bernsteinsäure wiederholt, dass die verbrauchte Anzahl ccm der Basen ungefäbr dieselben waren wie vorher. Gefunden wurde, theilweise zu verschiedenen Zeiten:

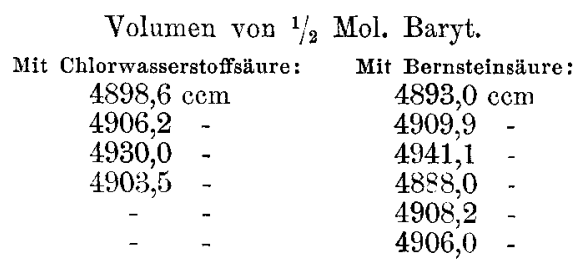

Differenz:

$$
\begin{aligned}
& -1,1 \text { pro mille. } \\
& +0,75 \\
& +2,25 \text { - } \\
& -3,1 \text { - } \\
& +1,0 \\
& +0,5
\end{aligned}
$$

Mit kohlensäurefreier Natronlauge ${ }^{1}$ ) wurden die folgenden Resultate erhalten:

$$
\begin{aligned}
& \text { Volumen von } 1 \text { Mol. Natron. } \\
& \text { - nachher } 2039,3 \text { - } 2033,9 \text { - } \\
& 2038,5
\end{aligned}
$$

Durch Wägen, statt Messen, der alkalischen Lösungen kann wohl noch grössere Genauigkeit erreicht werden. Mittels der genau bestimmten Lösungen kann selbstverständlich die Titerstellung von Normalsäuren geschehen.

Die Bernsteinsäure löst sich, pulverisirt, schnell in Wasser; die Lösung bleibt beim Versetzen sowohl mit Barytwasser wie mit Natronlauge vollständig klar und der Übergang (zur schwachen Rosafarbe) ist vorzüglich scharf; derselbe wird unzweideutig mit $1 / 30 \mathrm{ccm}$ des ca. $1 / 5$ Normal-Barytwasser hervorgerufen. Man trocknet die Bernsteinsäure am besten bei ca. $70^{\circ}$ bis zum constanten Gewicht; eine Stunde genügt für $0,5-1,0 \mathrm{~g}$ der pulverisirten Säure. Bei höherer Temperatur, schon bei wenig über $100^{\circ}$, scheint eine beginnende Anhydridbildung eintreten zu können.

\section{Neuer Rückflusskugelkühler (nach Dr. Martin Singer). \\ Von Dr. Peters \& Rost, Berlin.}

Dieser Kühler (Fig. 1) besteht aus zwei concentrischen Kugeln. Die äussere Kugel wird durch ein Rohr mit dem Destillationsgefäss verbunden. Das Kühlwasser tritt durch ein Rohr in die innere Kugel nahe am Boden ein, füllt die-

1) Dieselbe wurde folgendermaassen dargestellt: Reines, zweifach umkrystallisirtes, kohlensaures Natron wurde mit gelöschtem Kalk, aus isländischem Doppelspath bereitet, in einem geräumigen Kolben ron Jenaer Normalglas caustificirt. Der Kolben war mit Rückflusskühler versehen, der oben durch eine Natron-Kalkrölre gegen die Luft geschützt war. Nach Beendigung des Processes und Erkalten wurde der Kühler entfernt und statt dessen sofort ein zweimal durchbohrter Gummistöpsel eingesetzt; durch die eine Durchbohrung ging eine NatronKalkröhre, durch die andere eine gebogene Glasröhre, die so weit hinab reichte, dass die klare Lange aufsteigen konnte und aussen mit der (gleichfalls geschützten) Bürette in Verbindung stand. Die Lauge zur Titrirung kann auf diese Weise vollständig kohlensäurefrei in die Bürette getrieben werden; sie enthält Spuren von Kieselsüure, die indess für die Bestimmung der Alkalität ganz unwesentlich sind. 